\title{
METHODS AND TECHNIQUES FOR DESIGN OF EFFECTIVE AND COMPETITIVE SINGLE WAGON LOAD TRANSPORTATION
}

European freight railway operators are losing money with their single wagon load transportation activities. Closing down this business segment does not appear to be a valid option, since single wagon load transportation is connected with full train load business and intermodal traffic. This paper presents methods and techniques that were chosen to solve different problems of single wagon load transportation.

Key words: single wagon load transportation, location-allocation problem, computer simulation

\section{Introduction}

Single wagon load traffic has been one of the basic offerings of railway companies ever since the railways were created. Over more than a century and a half, this product has undergone several major phases. For almost 100 years there was a constant increase in the volume of wagon loads transported. As road haulage began to grow in the 1960s, the number of single wagon loads carried started to decline. In the 1990s, the predominant view was that single wagon load traffic had no future and would be completely superseded by combined transport. The last few years, however, have seen a turning point, with interest in this service growing again, including among private railway operators [5].

The client will choose single wagon load transportation when he wants to dispatch one or several wagons at the time but does not have enough quantity to fill a full train.

Logistically the system of single wagon load transportation is comparable with a "hub and spoke system" (a system where all goods are brought into a central point - the hub - for sorting and are distributed out from the centre in all directions). It is a network system which consists of customer sidings, stations and marshalling yards [7]:

- If the customer has railway tracks, the operator will send a feeder service to collect the wagons (and give the customer empty wagons to fill). These are then hauled or pulled to a marshalling yard (assembly point for the goods to compromise a wagon load).

- If the client does not have railway track access, he will transport the goods to a terminal by truck where the goods are loaded onto a railway wagon and then brought to the marshalling yard.

- In the marshalling yard further wagons (from other customers) are added and the train is built up for departure to the next hub / marshalling yard in the network. All departures within the network are scheduled and depart at predefined times.
- The wagons are transported from one hub/ marshalling yard to another and wagons are added and taken away at each stop.

- Once the wagon has reached the hub nearest to its destination, it is taken off the train and is transported either by truck or by track to the final destination.

\section{Specification of problems to be solved in system of single wagon load transportation}

As mentioned above, there are two main processes that exist in the system of single wagon load transportation:

- Wagon transportation among the origin station, marshalling yards and destination station,

- Sorting of wagons in marshalling yards.

The management and control of these processes have significant influence on the client satisfaction and service efficiency. These two processes cannot be organized independently because of their interaction. Different problems can be detected during management and planning of this system, because of complexity of both processes:

- Location of "hubs" in the network,

- Allocation of railway stations (origin or destination) or private sidings of a client to the hubs,

- Specifying a number of trains among marshalling yards (called as direct long-distance trains) and trains that pick up the wagons from origin stations and distribute the wagons to the destination stations (called local freight trains),

- Specifying the composition of direct long-distance trains - oneblock trains vs. block trains,

- Specifying routes of local freight trains,

- Specifying the composition of local freight trains,

- Organization of wagon sorting in marshalling yards,

- Developing sorting schemes for secondary sorting in connection to the formation of local freight trains.

\footnotetext{
* Michal Kohani, Peter Marton

Department of Transportation Networks, Faculty of Management Science and Informatics, University of Zilina, Slovakia,

Email: Michal.Kohani@fri.uniza.sk
} 
Different methods of operation research can be used to solve the mentioned problems.

\subsection{Location of "hubs" in the network and allocation of origin/destination stations}

A single wagon load transportation system is a transportation system, which has approximately the same number of primary sources as number of customers and provides transport of carriages between railway stations. Such a system is called "hub and spoke system". In this case, demands of customers form a matrix of yearly flows of carriages from source railway stations to destination railway stations. We denote this matrix as $B=\{b s j\}$, for $s \in S$ and $j \in J$, where $S$ is a set of source railway stations and $J$ denotes a set of destination railway stations. The fact that the unit cost of transportation is smaller when bigger bulks of items are transported, approves concentration of flows between different pairs of source and customer to stronger flows at least on a part of their way. This flow concentration needs marshalling yards, in which transshipment of transported items is performed and bigger bulks are formed or, on the other hand, where bulks (direct trains) are split into smaller groups (manipulating trains) designated to different destination railway stations.

Contrary to the classical distribution systems, in which big bulks leave a primary source, another situation emerges in this distribution system. Primary sources send relatively small bulks of items and it is useful to concentrate them to bigger bulks in the marshalling yards located near the sources and then to send these bigger bulks to remote marshalling yards and to split them there (see Fig. 1).

We restrict here to the system, in which a railway station is assigned to only one marshalling yard and an exchange of the consignments between this station and other stations is done via the assigned marshalling yard, as it is shown in Fig. 1. Furthermore,

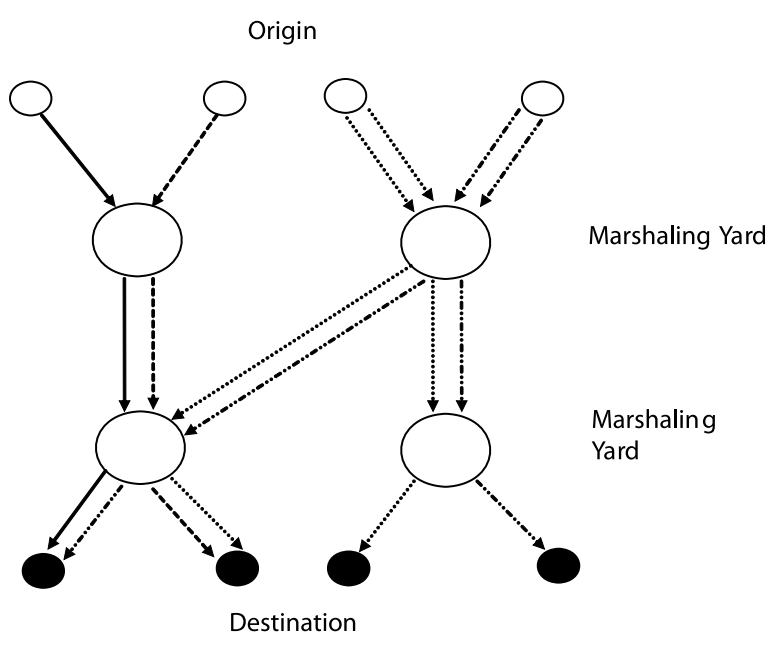

Fig. 1 Scheme of hub and spoke system we consider the general case, in which any origin station is simultaneously a destination station.

We do not make any difference between an origin station and a destination station hereafter and we introduce in general the set $J^{\prime}$ of railway stations.

The matrix $B$ gives by coefficients $b_{s j}$ the yearly volume of the carriages, which are sent from the object $s$ to the object $j$ and it gives by coefficients $b_{j s}$ the total yearly volume sent from the object $j$ to the object $s$. In the next section we try to model a symmetrical many-to-many distribution system with a unique assignment of customers to terminals.

Let us consider a case with a linear cost estimation function with the unit cost $e_{0}$ for transport of one item along the unit distance on the way from an origin railway station to a marshalling yard or from a marshalling yard to a destination railway station. Let us consider the unit cost $e_{1}$ for transport of one item along the unit distance on the way from one to other marshalling yards. Furthermore we denote a set of possible terminal locations by the symbol $I$, where each place $i \in I$ is associated with the yearly fixed charge $f_{i}$ for building and performance of a terminal at the location $i$ and with the unit cost $g_{i}$ for transshipment of one unit in the terminal. In accordance to the previous definition, we denote $J^{\prime}$ the set of objects which mutually send carriages with the yearly total amounts bsj from $s \in J^{\prime}$ to $j \in J^{\prime}$. The symbol dij denotes the distance between the locations $i$ and $j$. Our objective is to assign each sending or receipting object to exactly one terminal so that the total yearly cost of the designed system is minimal. If we denote by $y_{i} \in\{0,1\}$ for $i \in I$ the bivalent variable, which corresponds to the decision if a marshalling yard will or will not be built at the place $\mathrm{i}$ and if we introduce the variable $z_{i j} \in\{0,1\}$ for $i \in I$ a $j \in J^{\prime}$, which says if the station $j$ will or will not be assigned to the place $i$, than we can formulate the following mathematical programming model of problem:

Minimise

$$
\begin{aligned}
& \sum_{i=1}^{m} f_{i} y_{i}+\sum_{i=1}^{m} \sum_{j=1}^{n}\left(e_{0} d_{i j}+g_{i}\right)\left(\sum_{s=1}^{n} b_{j s}+\sum_{s=1}^{n} b_{s j}\right) z_{i j}+ \\
& +\sum_{i=1 k=1}^{m} \sum_{1}^{m} e_{1} d_{i k} \sum_{j=1 s=1}^{n} \sum_{s j}^{n} b_{s} z_{i j} z_{k s} . \\
& \text { Subject to } \sum_{i=1}^{m} z_{i j}=1 \text { for } j=1, \ldots, n, \\
& z_{i j} \leq y_{i} \quad \text { for } i=1, \ldots, m, j=1, \ldots, n, \\
& y_{i} \in\{0,1\} \text { for } i=1, \ldots, m, \\
& z_{i j} \in\{0,1\} \text { for } i=1, \ldots, m, j=1, \ldots, n .
\end{aligned}
$$

The model belongs to discrete quadratic programmes due the third term of (1) 


\subsection{Application of computer simulation}

By organization of wagon sorting and development of sorting schemes for secondary sorting the usage of exact mathematical techniques is considerably restricted because of the system complexity and stochastic behavior. On the other hand, the classic planning techniques use very simplified operation models, which do not take into account stochastic behavior of the system and are not able to provide the possibility of observation of independent dynamic technological processes. Average values, standards and expert's knowledge are used instead. An only practicable way how to reach the required level of results plausibility is to use the computer simulation. The computer simulation can be used by checking the ability of a marshalling yard to handle all inbound and outbound trains that were scheduled to terminate or originate there according to the result gathered from solution of previous problems too.

The choice of a suitable simulation tool is very important in this case. By simulation of processes in a marshalling yard it is necessary to meet a certain detail of the model. We recommend the use of microscopic simulation for this case. Thanks to this it will be possible to simulate and consider all the trains, engines and wagons movements, sorting of wagons on hump or classification lead, "on-line" occupation of all the infrastructure parts and work of all personnel. Detailed animation of the processes modeled is very important in case of marshalling yard simulation too.

Another criterion for choice of a simulation tool is its proposition of simulation run evaluation. Many types of railway-specific statistics and protocols are needed by decision-making about ability or non-ability of a marshalling yard to handle the processes planed, e.g. use of switches, filling of classification tracks.

\section{Realized parts of research}

At present we are working on the solving of location-allocation problem and preparation of simulation models of marshalling yards.

\subsection{Tool for decision-making about hubs location}

The tool for decision making about hubs location (see Fig. 2) allows the user to compare various possibilities of hubs location, which are based on a different set of input parameters.

This tool works on the network of Slovakian cargo railways. The input parameters, which can't be changed by the user are the distance matrix and the matrix of yearly flows of carriages from source railway stations to destination railway stations. These parameters were obtained from the project [2].

Input parameters which can be changed by the user are fixed cost for each marshaling yard candidate, cost for transshipment of one wagon in terminal, locations of marshaling yards candidates, unit transportation cost $e_{0}$ and $e_{1}$. These parameters values are pre-set with the data from the project [2], but the user is allowed to change it and obtain various solutions which depend on various possible situations and scenarios. All adjusted parameters can be saved to the text file and can be used for afterwards application.

Having set the parameters the problem can be solved. The solving method based on the approximate linearization of the model (1)-(5) and the Beta_is adaptation of the model is used [3]. This solving method can provide the user with the solution in a very short time and the quality of the solution is very high.

Having solved the problem the software allows the user to see the solution on the map, where all the selected marshaling yards are shown. After selecting the marshaling yard from the list or on the map, all the stations allocated to the marshaling yard are shown.

The solution can be saved in the Excel file format and can be used for further application or comparison of various alternatives.

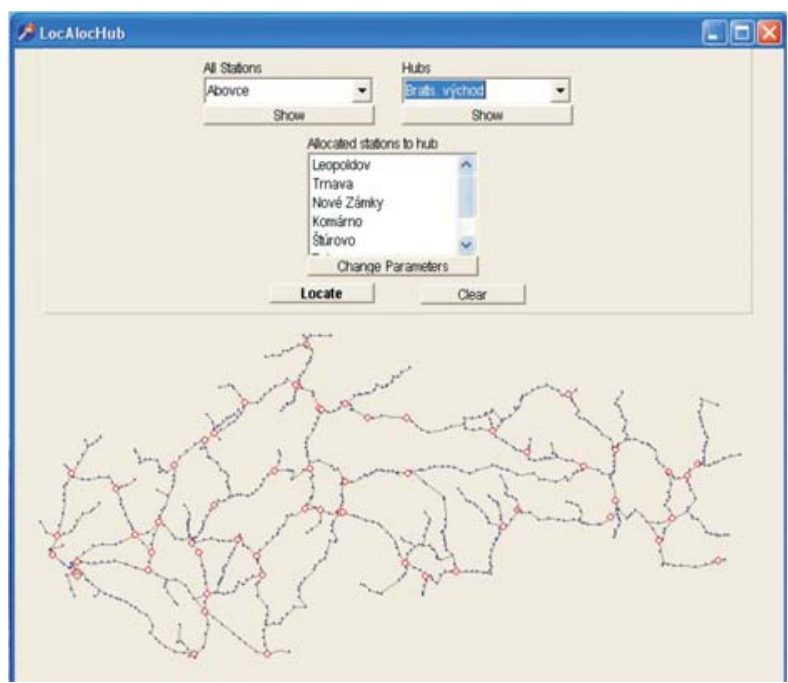

Fig. 2 Screenshot of tool for hubs location

\subsection{Application of described methods and techniques - model of single wagon load transportation in Slovakia}

Considering the specific requirements described in part 2.2, we recommend to use the Villon simulation tool for this purpose. Up to now the simulation models of many marshalling yards have been built with the help of Villon. We can mention especially the following marshalling yards: Wien Zvbf, Linz Ost Vbf, Hamburg Alte Süderelbe, Basel SBB RB I and Lausanne Triage. Experts from Austria, Germany [6], Switzerland [4] and China have already measured the qualities and properties of Villon. The Villon simulation tool was developed in cooperation of the University of Zilina, Faculty of Management Science and Informatics and SIMCON 


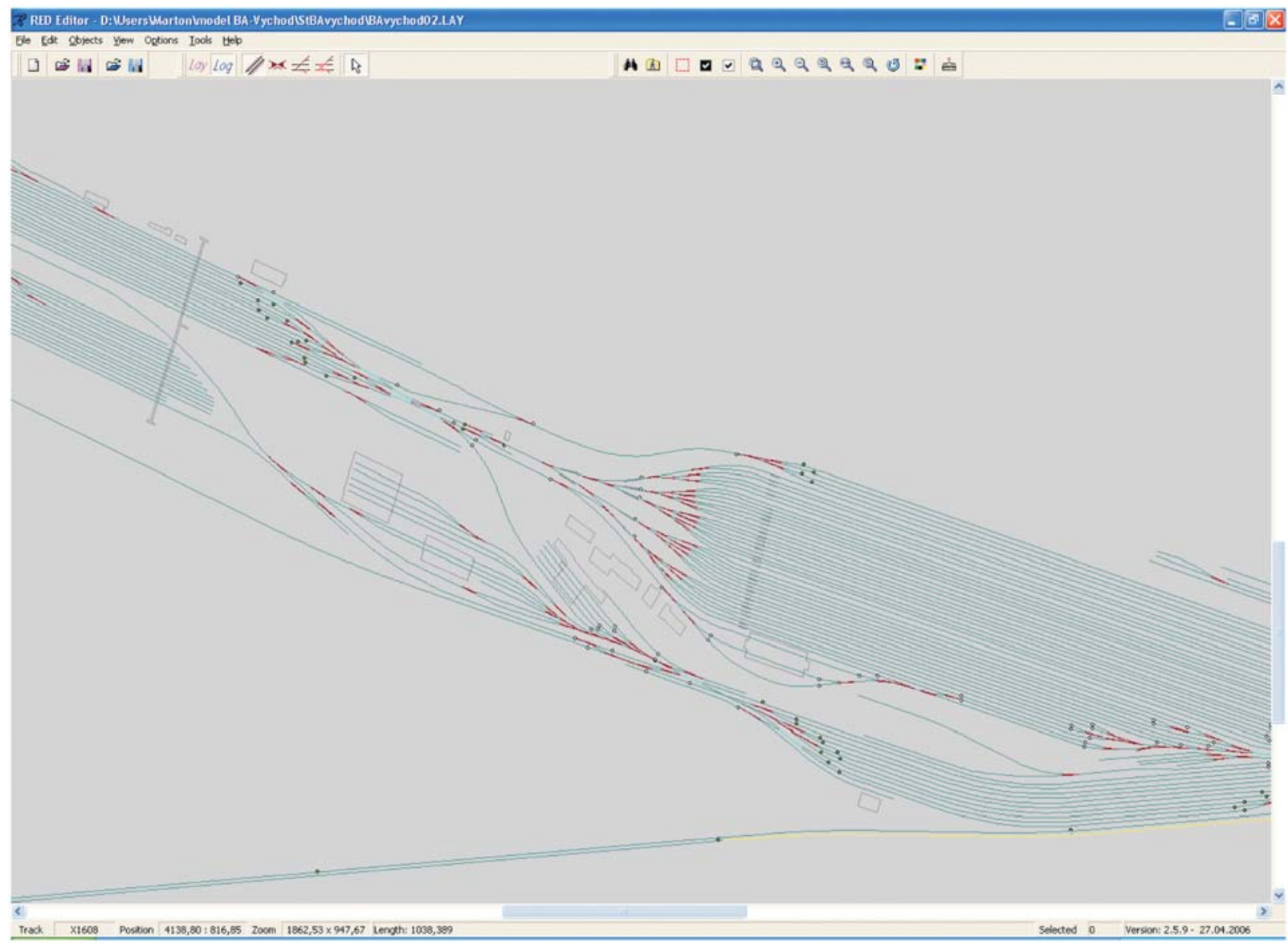

Fig. 3 Detail of infrastructure model of Bratislava vychod marshalling yard

s.r.o. Zilina. More about the properties of Villon simulation tool can be found in [1].

The construction of a simulation model of Bratislava východ marshalling yard has already started. Bratislava vychod marshalling yard is the most important marshalling yard in the Slovak railway network. It is located in Bratislava railway junction, close to Hungarian and Austrian borders. This marshalling yard can be used as a hub for about $12000 \mathrm{~km}^{2}$ and about $900 \mathrm{~km}$ of lines.

The work on the model development can be divided to several phases:

1. defining the input data - collecting, processing and analyzing the station data,

2. creation of an infrastructure model,

3. creation of a dynamic operation model,

4. experimenting with the simulation model,

5. analysis of the experiment results

Phases 1 and 2 have already been finished. Fig. 3 shows the infrastructure model of Bratislava vychod marshalling yard. Phase 3 has started but the work does not continue at present. Until now all the important data about personnel and engines have been defined in the dynamic simulation model. It is necessary to wait for the results from the design of hubs networks and determination of numbers and routes of freight trains. Thanks to these result we will have important information about freight trains timetable, primary sorting schemes and secondary sorting schemes. Then, phase 3 can continue.

\section{Conclusion}

Single wagon load transportation is a very flexible system which gives the customer full adaptability in terms of dispatch volatility. Basically the client can choose how many wagons he wants to dispatch. From one day to another the quantity of dispatched wagons can vary. He can decide when to load the wagons, which is a major benefit to the trucks which very often use a time slot loading system with penalties if they cannot dock at the right time. As the routes are fixed in advance, the customer can as soon as he needs to, add wagons to a train.

With an annual freight volume of around 100 billion tkm, single wagon load transportation accounts for approximately $50 \%$ of Europe's total rail market. This kind of transport is a crucial supply 
chain element for Europe's predominantly midsized and geographically dispersed industry and agriculture [7].

We described the tools that can be used and that are developing to reach acceptable results in field of effective and competitive single wagon load transportation. The software developed for solving the location-allocation problem will be used not only for designing hubs networks and determining numbers and routes of freight trains. We assume that it would be possible to use it for the evaluation of different models of the infrastructure charging system and their influence to the costs and revenues of single wagon load service.

\section{Acknowledgement}

This work has been supported by the Slovak Grant Foundation under grant No. 1/4057/07 "Agent oriented models of service systems".

\section{References}

[1] ADAMKO, N., MARTON, P.: Villon - a tool for simulation of operation of transportation terminals, Communications - Scientific Letters of the University of Zilina, Vol. 10, 2/2008, p. 10-14, ISSN 1335-4205

[2] JANACEK, J. et all: Report of solving of initial study of 5.3 task "Software solution for optimization of transport work control" (in Slovak), Fakulta riadenia a informatiky, Zilinska univerzita, Zilina, 2001

[3] KOHANI, M.: Approximative methods for "many-to-many" distribution system design, Quantitative Methods in Economics (Multiple criteria decision making XIII): Proc. of the $13^{\text {th }}$ International Conference: Bratislava, University of Economics, ISBN 80-8078-129X. - P. 77-83, 2006

[4] KONIG, H.: VirtuOS - Simulieren von Bahnbetrieb Eisenbahntechnische Rundschau Nr. 1/2, Hestra-Verlag, Hamburg, 2001.

[5] MARTON, P.: Einzelwagenverkehr - gegenwärtige Situation in Europa, EI - Der Eisenbahningenieur. Jahrg. 59, 2008, p. 43-47. ISSN 0013-2810

[6] TALKE, W.: Effizienzsteigerung in Zugbildungsanlagen. Eisenbahtechnische Rundschau, Nr. 11 \& 12, Hestra-Verlag, Hamburg, 1998.

[7] UIC - Rail Freight Portal - http://www.uic.asso.fr/uic/spip.php?rubrique1166 